\title{
Fibroosseous Pseudotumor of the Digits
}

National Cancer Institute

\section{Source}

National Cancer Institute. Fibroosseous Pseudotumor of the Digits. NCI Thesaurus.

Code C6573.

A non-neoplastic soft tissue disorder characterized by the localized formation of reactive fibrous and bone tissues. It usually occurs in the subcutaneous tissue of the proximal phalanx. Less frequently, it involves the toe. It presents with swelling and pain of the affected area. The prognosis is excellent. However, incomplete excision may lead to the re-growth of the lesion. 